Thorax, 1978, 33, 483-487

\title{
Diaphragm and body weight in emphysema
}

\author{
WILLIAM M THURLBECK \\ From the Department of Pathology, University of Manitoba, Winnipeg, Canada
}

Thurlbeck, W M (1978). Thorax, 33, 483-487. Diaphragm and body weight in emphysema. The weight of the diaphragm has been investigated in 103 male patients and 81 female patients, and the relationship between body weight and emphysema has been assessed in 662 male and 431 female patients. Diaphragm weight is related to body weight in both male $(r=+0.76)$ and female patients $(r=+0.77)$ and is relatively larger in the former. Dissecting the diaphragm free of fat or freeze drying it does not appreciably improve the relationship between body weight and diaphragm weight. Diaphragm weight is better related to body weight than body length and is diminished in emphysema. Patients with emphysema weigh less. This is apparent with only moderate grades of emphysema, and there is no further loss of body weight as emphysema in the lung becomes more severe. The loss of diaphragm weight not only reflects the loss of body weight that occurs in emphysema, but the diaphragm is also less in weight than predicted from body weight. The diaphragm also appears abnormal on gross inspection in some patients with cmphysema. Heart weight and diaphragm weight are related, probably because both are related to body weight.

Alterations in the diaphragm in patients with cmphysema have attracted recent interest, but the data are conflicting. This is partly because authors have not always distinguished between chronic airflow obstruction (CAO) and emphysema and partly because the quantification of the lung lesions has sometimes been imprecise. Three studies have suggested that the diaphragm is hypertrophied. In one instance, this is an assertion without providing data (Wyatt et al, 1964) and was said to occur in severe emphysema. Ishikawa and Hayes (1973) noted an increase in thickness of the diaphragm in nine patients with CAO compared with 15 patients without CAO. Histologically, individual muscle fibres had increased in diameter in two patients with CAO that they studied. Scott and Hoy (1976) compared the crosssectional area of diaphragm muscle fibres as seen on histological slides in six non-emphysematous patients to the area of fibres seen in 18 patients with emphysema, varying from mild to severe. They found that the mean muscle fibre diameter was greater in patients with emphysema $\left(1069 \mu \mathrm{m}^{2}\right.$ compared to $851 \mu \mathrm{m}^{2}$ ). There was also a greater variation in muscle fibre size in patients with emphysema. There was no statistically significant relationship, however, between the extent of emphysema and the size of muscle fibres. All patients with emphysema had respiratory symptoms, and half of them died of airflow obstruction. The muscle fibres were larger in those who died of CAO. Scott and Hoy (1976) also observed a positive relation between weight of the ventricles of the heart and diaphragm muscle. Fromme (1916) had observed a correlation between heart weight and diaphragm weight.

Other authors have found good evidence that the diaphragm size decreases in emphysema. Diaphragm weight was found diminished in an older study from Germany of six emphysematous subjects (Fromme, 1916). Steele and Heard (1973) felt that area, volume, and thickness of the muscular part of the diaphragm was decreased in 17 "chronic bronchitics" compared to 27 controls. They considered that the amount of emphysema in the lungs was not a significant variable affecting diaphragm weight. Steele and Heard (1973) also showed a positive correlation between body weight and diaphragm volume and thickness. The bronchitic patients were underweight but diminution of diaphragm volume was greater than could be accounted for by the loss of body weight. No obvious change in the diaphragmatic muscle could be recognised histologically. They attempted to quantify muscle fibre size but found that there was such variation in muscle fibres in different 
parts of the diaphragm that they were unable to make a proper study. The most recent study (Butler, 1976) was also the largest (95 male patients). It showed a significant inverse correlation between diaphragm area and the extent of emphysema in the lungs. The reduction affected the muscular portion of the diaphragm, but in contrast to the previous study diaphragm thickness was not reduced.

\section{Materials and methods}

From 1 December 1971 to 30 November 1972 at least one lung was examined for emphysema from every necropsy performed at the Pathology Institute, McGill University, Montreal. During this period an attempt was made to examine every diaphragm. For various logistic reasons this was not possible. Diaphragms were also discarded when they were affected by inflammatory or neoplastic disease. Diaphragms were studied in 103 male and 81 female patients. The diaphragms were cut flush with the costal margins and the crura dissected from their vertebral origins. The pericardium was dissected free from the diaphragm, and the diaphragms were then weighed and photographed. Fat was then carefully dissected from the diaphragm, which was reweighed (fat-free weight). In 40 instances an approximately $10 \mathrm{~g}$ sample was then freeze dried and reweighed. The sample was assumed to be representative of the whole diaphragm and its dry weight was projected to the fat-free weight of the entire diaphragm. The bodies were weighed on a scale accurate to $0.1 \mathrm{~kg}$ and their crown-heel length was measured by a special pair of calipers, accurate to $0 \cdot 1 \mathrm{~cm}$. The lungs were distended for at least 14 hours at a transpulmonary pressure of $25 \mathrm{~cm}$ of formalin and were then cut into sagittal slices. A papermounted whole-lung section (Gough and Wentworth, 1958) was made from the mid-sagittal slice, and the amount of emphysema was assessed by three observers (M S Dunnill, R C Ryder, and W M Thurlbeck) who used a grading panel that scores the amount of emphysema on an arbitrary scale of 0-100 (Thurlbeck et al, 1970). The scores made by the three observers were averaged. The lungs were then divided into nine emphysema severity groups (ESG) depending on the amount of emphysema in the lungs. The number of cases and the range of emphysema scores in each ESG are shown in table 1 .

The patients' charts were examined and the patients divided into two groups: firstly, those who had severe CAO. If patients died of causes other than CAO the forced expiratory volume in
Table 1 Number of cases and emphysema scores in each emphysema severity group (ESG)

\begin{tabular}{lcll}
\hline ESG & Emphysema score & No of cases & \\
& & $M$ & $F$ \\
\hline 1 & 0 & 24 & 27 \\
2 & $1-4$ & 20 & 19 \\
3 & $5-14$ & 16 & 17 \\
4 & $15-24$ & 15 & 7 \\
5 & $25-34$ & 7 & 6 \\
6 & $35-44$ & 8 & 2 \\
7 & $45-54$ & 4 & 2 \\
8 & $55-64$ & 2 & 1 \\
9 & $\geq 65$ & 7 & 0 \\
\hline
\end{tabular}

1 second $\left(\mathrm{FEV}_{1}\right)$ had to be equal to or less than $40 \%$ of predicted and/or the maximum midexpiratory flow rate (MMFR) was less than or equal to $25 \%$ of predicted. Most patients who died of CAO also had tests of expiratory function that were similarly altered, and secondly, the remaining patients who were considered not to have severe CAO.

A further group of cases was also used to examine the relationship between body weight and the amount of emphysema in the lungs. This group included the patients described above and consisted of all patients from whom a paper-mounted whole-lung section had been made from the midsagittal slice of a formalin-distended lung. Other than for the cases above, the body weights of these patients were those recorded in their necropsy records. The assessments of the amount of emphysema and CAO were the same as in the smaller group of cases.

\section{Results}

The regression line of the relationship between diaphragm weight and body weight for male and female patients with no (ESG 1) or equivocal or 옥 trivial emphysema (ESG 2) is shown in fig 1. The $>$ relationship is good for both male $(r=+0.76$, ㅡㅡ․ $P<0.001)$ and female $(r=+0.77, \quad P<0.001)$ N patients. In the useful range of body weight, diaphragm weights are larger in male than in female patients. The relationship between $\mathrm{W}$ diaphragm weight and body length was less good $(r=+0.37, \quad P<0.05)$ in male and $(r=+0.18$, $P<0.1)$ in female patients. The relationship be- $\mathbb{\Phi}$ tween body weight and fat-free diaphragm weight $\stackrel{\mathcal{C}}{\rightarrow}$ $\left(\mathrm{r}=+0.69\right.$ for male and +0.76 for female patients) $\frac{0}{0}$ was no better than the relationship between body $\underset{\mathbb{D}}{\stackrel{0}{0}}$ weight and diaphragm weight with attached fat. The relationship between dry diaphragm weight $\stackrel{\mathbb{Q}}{\complement}$ and body weight was good $(r=+0.82$ in both sexes) but was not significantly better than whole 8 diaphragm weight. There thus appears to be no $\frac{0}{0}$ 


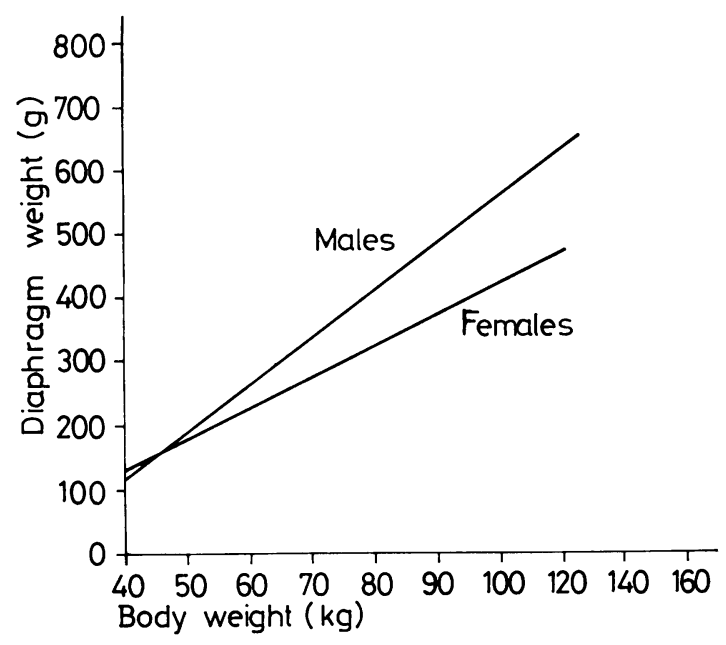

Fig 1 Regression lines between body weight $(B W)$ and diaphragm weight $(D W)$ are illustrated for male patients $(r=+0 \cdot 76, \mathrm{P}<0.001, D W=7 \cdot 241)$ $B W-173 \cdot 5)$ and for female patients $(r=+0 \cdot 77$, $\mathrm{P}<0.001, D W=4.841 / B W=64.23)$.

significant advantage in using assessments of diaphragm weight other than its original weight and this will be used subsequently.

Diaphragm weight in male patients is plotted against ESG in fig 2, and this illustrates that the diaphragm decreased in weight as the amount of emphysema in the lungs increased $(r=-0.26$, $\mathbf{P}<0.05$ ). Figure 3 shows that in the whole series body weight decreases as the amount of emphy-

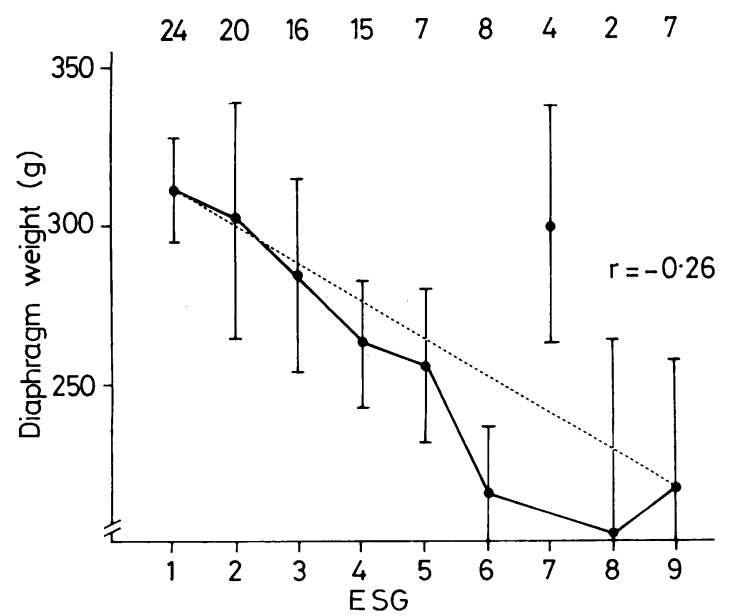

Fig 2 Mean diaphragm weight ( $\pm 1 S E)$ is shown in each emphysema severity group (ESG) in male patients. sema increases. The same was true of the smaller group of cases in which diaphragm weight was available. Since there are many fewer cases, there is more variation in this relationship. The body weight decrease is first apparent in ESG 4 (fig 3), and there is little subsequent decrease in body weight. For example, body weight is no different in ESG 7, 8, 9 compared with ESG 4, 5, 6 (table 2). In both sexes diaphragm weight is significantly $(\mathrm{P}<0.01)$ less in ESG 4, 5, 6 compared with ESG 1, 2, 3. This is not only due to loss of diaphragm weight associated with loss of body weight but it is also due to specific loss of diaphragm weight since the ratio of diaphragm weight to body weight is less in ESG 4, 5, 6 (table 3 ). There are too few female cases to consider diaphragm weight in ESG 7, 8, 9 but in male cases the absolute diaphragm weight is slightly diminished. Relative diaphragm weight, however, is significantly $(\mathrm{P}<0.05)$ lower in ESG 7, 8, 9 than ESG 4, 5, 6. Table 2 also compares body weight in patients with varying severity of CAO.
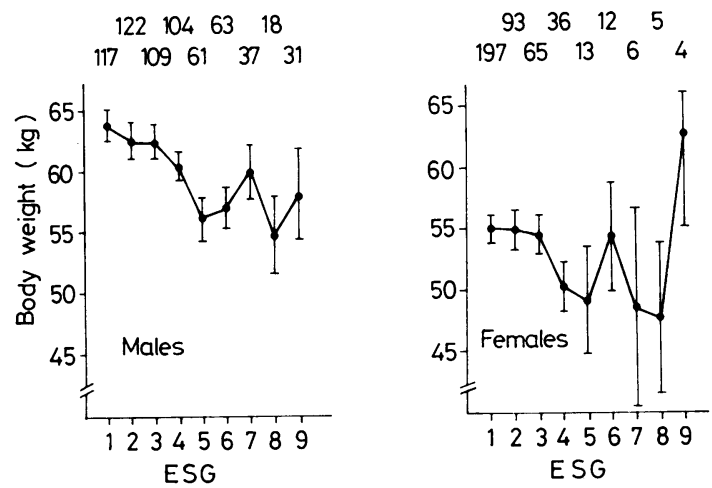

Fig 3 Average body weight is shown in each ESG in both male and female patients in all cases available for study.

In all categories of emphysema body weight is less in male patients with severe CAO but this does not reach statistically significant levels. No trend is apparent in female patients. Only six patients whose diaphragms were weighed had severe CAO: the five male patients had a low diaphragm weight (average $241 \mathrm{~g}$ ) and a low relative diaphragm weight $(3.95 \mathrm{~g} / \mathrm{kg})$ compared to the remainder. Four of the five, however, had significant emphysema (one in ESG 4, 5, 6 and three in ESG 7, 8, 9). Thus there are too few cases to consider the separate effect of CAO from the severity of emphysema.

Heart weight is related to body weight 
Table 2 Average body weight is compared in patients grouped by ESG and in patients with and without severe chronic airflow obstruction $(C A O)$

\begin{tabular}{|c|c|c|c|c|c|c|c|}
\hline & & \multicolumn{2}{|c|}{$E S G 1,2,3$} & \multicolumn{2}{|c|}{$E S G 4,5,6$} & \multicolumn{2}{|c|}{$E S G 7,8,9$} \\
\hline & & No & $\begin{array}{l}\text { Body weight } \\
\text { (kg) }\end{array}$ & No & $\begin{array}{l}\text { Body weight } \\
(\mathrm{kg})\end{array}$ & No & $\begin{array}{l}\text { Body weight } \\
(\mathrm{kg})\end{array}$ \\
\hline Male patients: & $\begin{array}{l}\text { Without severe CAO } \\
\text { With severe CAO }\end{array}$ & $\begin{array}{r}343 \\
5\end{array}$ & $\begin{array}{l}62 \cdot 2 \pm 0 \cdot 80 \\
59 \cdot 5 \pm 8 \cdot 6\end{array}$ & $\begin{array}{r}196 \\
32\end{array}$ & $\begin{array}{l}58 \cdot 5 \pm 0 \cdot 90 \\
57 \cdot 0 \pm 2 \cdot 42\end{array}$ & $\begin{array}{l}46 \\
40\end{array}$ & $\begin{array}{l}59 \cdot 2 \pm 2.91 \\
57.0 \pm 1 \cdot 74\end{array}$ \\
\hline Female patients: & $\begin{array}{l}\text { :Without severe CAO } \\
\text { With severe CAO }\end{array}$ & $\begin{array}{r}344 \\
11\end{array}$ & $\begin{array}{l}54.9 \pm 0.82 \\
56 \cdot 5 \pm 2 \cdot 34\end{array}$ & $\begin{array}{l}51 \\
10\end{array}$ & $\begin{array}{l}50 \cdot 6 \pm 1 \cdot 80 \\
52 \cdot 3 \pm 5 \cdot 0\end{array}$ & $\begin{array}{l}9 \\
6\end{array}$ & $\begin{array}{l}52 \cdot 8 \pm 5 \cdot 45 \\
51 \cdot 3 \pm 7 \cdot 65\end{array}$ \\
\hline
\end{tabular}

Table 3 Ratio of diaphragm weight $(D W)$ to body weight $(B W)$ is compared in patients with varying degrees of emphysema

\begin{tabular}{|c|c|c|c|c|c|c|}
\hline & \multicolumn{2}{|c|}{ ESG $1,2,3$} & \multicolumn{2}{|c|}{$E S G 4,5,6$} & \multicolumn{2}{|c|}{$E S G 7,8,9$} \\
\hline & No & $\begin{array}{l}D W / B W \\
g / k g\end{array}$ & No & $\begin{array}{l}D W / B W \\
g / k g\end{array}$ & No & $\begin{array}{l}D W / B W \\
g / k g\end{array}$ \\
\hline Male patients & 60 & $4 \cdot 61 \pm 0 \cdot 15$ & 30 & $4 \cdot 33 \pm 0 \cdot 13$ & 13 & $4 \cdot 00 \pm 0.20$ \\
\hline Female patients & 63 & $3.62 \pm 0.09$ & 15 & $3 \cdot 40 \pm 0 \cdot 15$ & 3 & $3.47 \pm 0.34$ \\
\hline
\end{tabular}

$(\mathrm{r}=+0.48, \mathrm{p}<0.01)$ as well as to diaphragm weight $(\mathrm{r}=+0.47, \mathrm{P}<0.01)$.

\section{Discussion}

These results clearly indicate that the diaphragm weight is diminished in patients with emphysema. This is partly due to the fact that patients with emphysema tend to be underweight. In addition, however, the diaphragm is lower in weight than predicted from body weight. The results are therefore similar to those of Butler (1976) who found diminished diaphragm muscle area in patients with emphysema. Our results differ from his in that we have shown a close relationship between diaphragm weight and body weight, which he did not observe. We also observed a poor relationship between diaphragm size and body length, whereas the relationship observed by him was better. It might be anticipated that the relationship between body weight and diaphragm weight would be better than between body length and diaphragm weight in a necropsy population because of the extreme variations in weight in patients dying of various causes. Many patients are cachectic whereas others are grossly oedematous. Steele and Heard (1973) observed a relationship between body weight and diaphragm volume. Our results differ from theirs in that emphysema and diaphragm weight are negatively related in this series, whereas in their series the relationship was between "chronic bronchitis" and diaphragm volume. Not only is the diaphragm quantitatively abnormal in emphysema, but in many instances it is also abnormal in appearance. In emphysema the costal origins of the diaphragm form bands, s which in many instances are recognised to be separate from each other, and the intervening diaphragm may be translucent. It is these bands of $\stackrel{\complement}{\complement}$ muscle that are presumably responsible for the $\overrightarrow{\overrightarrow{0}}$ grooves (Leibermeister grooves) seen on the su- 3 perior aspect of the liver in some patients with emphysema and CAO.

The data are inadequate to assess whether CAO has an effect on the diaphragm separate from으 emphysema. There is a trend in male patients for $\ddot{x}$ body weight to be less in patients who have severe CAO than in patients with similar amounts of emphysema but who do not have severe CAO. It is thus possible that diaphragm weight may be even lighter for a given amount of emphysema in 윽 patients with CAO.

This study started off with the rather naive belief을 that the weight of the diaphragm might be a goodn indication of the work of breathing and might thus be a method of assessing the ventilatory re- $N$ sponse of patients to CAO. It is, however, ap- $\omega$ parent that the diaphragm is at a disadvantage in patients with CAO, especially those with emphye sema. McKenzie et al (1972) showed that the extent of diaphragmatic motion was inversely re-? lated to the amount of emphysema in the lungs. 0 Sharp et al (1977) showed that about one-quarter of ambulatory patients with CAO and eight of ten@ patients with CAO and acute respiratory failure $\stackrel{\odot}{\Omega}$ showed inward abdominal motion coincident witho outward rib cage motion during inspiration. This pattern was similar to that observed in patientso 
with paralysis of the diaphragm, and they felt that this breathing pattern represented ineffective diaphragmatic action. Indeed, ascent of the diaphragm was seen during inspiration in three of five ambulatory patients with abnormal respiratory movements. The patients with these movements tended to have type A (emphysematous) CAO, severe CAO, and high residual volumes. Ashutosh et al (1975) have also described asynchronous rib cage and abdominal breathing movements in patients with CAO. It seems likely that the flattened position of the diaphragm, with consequent lessening of its radius of curvature, renders it relatively ineffective as an inspiratory muscle.

It is interesting that the diaphragm is larger relative to body weight in male than female patients. Diaphragm position at total lung capacity is lower in male than female patients (Thurlbeck and Simon, 1978), which suggests that it is capable of more forceful contraction in male patients. Diaphragm muscle is enlarged in manual labourers (Fromme, 1916) so that the relatively increased diaphragmatic muscle mass in men may represent increased physical activity on the part of male subjects.

The loss of body weight in emphysema is also of interest. This is a well-recognised phenomenon and seems to be primarily related to diminished caloric intake (Wilson et al, 1964). The present data show that the loss in body weight becomes apparent in patients with mild to moderate emphysema (ESG 4) and does not get worse as emphysema gets more severe. The reasons for this are not clear.

A relationship between heart weight and diaphragm weight is also apparent in our data, as it has been in others (Fromme, 1916; Scott and Hoy, 1976). This relationship probably exists because both are related to body weight.

Like Steele and Heard (1973), we were unable to devise a satisfactory method for histological assessment of diaphragm atrophy or hypertrophy. Not only is sampling a problem because of the different components of the diaphragm but it is essential to get exact cross-sectional sections of muscle fibres since oblique sectioning may greatly increase the apparent cross-sectional area of muscle fibres. It may be that an alteration in the configuration of diaphragmatic muscle results in obliquity of sectioning of muscle fibres accounting for the results observed by Scott and Hoy (1976).

This study was supported by Medical Research Council of Canada grants MT-1296 and DG-152.

\section{References}

Ashutosh, K, Gilbert, R, Auchincloss, J H jun, and Peppi, D (1975). Asynchronous breathing movements in patients with chronic obstructive pulmonary disease. Chest, 67, 553-557.

Butler, C (1976). Diaphragmatic changes in emphysema. American Review of Respiratory Disease, 114, 155-159.

Fromme, H (1916). Systematische Untersuchungen über die Gewichtsverhältnisse des Zwerchfells. Virchows Archiv für pathologische Anatomie und Physiologie und für Klinische Medizin, 221, 117155.

Gough, J, and Wentworth, J E (1959). Thin sections of entire organs mounted cn paper. Harvey Lectures, 1957-8, 53, 182-185.

Ishikawa, S, and Hayes, J A (1973). Functional morphometry of the diaphragm in patients with chronic obstructive lung disease, American Review of Respiratory Disease, 108, 135-138.

McKenzie, H I, Outhred, K, and Glick, M (1972). Post-mortem evaluation of the use of diaphragmic excursus in assessment of pulmonary emphysema in coal miners. Thorax, 27, 359-364.

Scott, J W M, and Hoy, J (1976). The cross-sectional area of diaphragmatic muscle fibres in emphysema, measured by an automated image analysis system. Journal of Pathology, 120, 121-128.

Sharp, J T, Goldberg, N B, Druz, W S, Fishman, H C, and Danon, J (1977). Thoracoabdominal motion in chronic obstructive pulmonary disease. American Review of Respiratory Disease, 115, 47-56.

Steele, R H, and Heard, B E (1973). The size of the diaphragm in chronic bronchitis. Thorax, 28, 55-60.

Thurlbeck, W M, Dunnill, M S, Hartung, W, Heard, B E, Heppleston, A G, and Ryder, R C (1970). A comparison of three methods of measuring emphysema. Human Pathology, 1, 215-226.

Thurlbeck, W M, and Simon, G (1978). The radiographic appearance of the chest in emphysema. American Journal of Roentgenology, Radium Therapy, and Nuclear Medicine, 130, 429-440.

Wilson, N L, Wilson, R H L, and Farber, S M (1964). Nutrition in pulmonary emphysema. Journal of the American Dietetic Association, 45, 530-536.

Wyatt, J P, Fischer, W V, and Sweet, H C (1964). The pathomorphology of the emphysema complex. American Review of Respiratory Disease, 89, 533560 and 721-735.

Requests for reprints to: Dr W M Thurlbeck, Department of Pathology, University of Manitoba, Winnipeg, Canada. 